\title{
Full quantification of selenium species by RP and AF-ICP-qMS with on-line isotope dilution in serum samples from mercury-exposed people supplemented with selenium- enriched yeast
}

Li, Yu-Feng; Hu, Liang; Li, Bai; Huang, Xiaohan; Larsen, Erik Huusfeldt; Gao, Yuxi; Chai, Zhifang; Chen, Chunying

Published in:

Journal of Analytical Atomic Spectrometry

Link to article, DOI:

10.1039/c0ja00129e

Publication date:

2011

Document Version

Publisher's PDF, also known as Version of record

Link back to DTU Orbit

Citation (APA):

Li, Y-F., Hu, L., Li, B., Huang, X., Larsen, E. H., Gao, Y., Chai, Z., \& Chen, C. (2011). Full quantification of selenium species by RP and AF-ICP-gMS with on-line isotope dilution in serum samples from mercury-exposed people supplemented with selenium-enriched yeast. Journal of Analytical Atomic Spectrometry, 26(1), 224-229. https://doi.org/10.1039/c0ja00129e

\section{General rights}

Copyright and moral rights for the publications made accessible in the public portal are retained by the authors and/or other copyright owners and it is a condition of accessing publications that users recognise and abide by the legal requirements associated with these rights.

- Users may download and print one copy of any publication from the public portal for the purpose of private study or research.

- You may not further distribute the material or use it for any profit-making activity or commercial gain

- You may freely distribute the URL identifying the publication in the public portal 


\title{
Full quantification of selenium species by RP and AF-ICP-qMS with on-line isotope dilution in serum samples from mercury-exposed people supplemented with selenium-enriched yeast $\dagger$
}

\author{
Yu-Feng Li, ${ }^{a}$ Liang Hu, ${ }^{a}$ Bai Li, ${ }^{a}$ Xiaohan Huang, ${ }^{a}$ Erik H. Larsen, ${ }^{c}$ Yuxi Gao, ${ }^{a}$ Zhifang Chai ${ }^{a}$ \\ and Chunying Chen *ab
}

Received 20th August 2010, Accepted 5th November 2010

DOI: 10.1039/c0ja00129e

\begin{abstract}
Accurate determination of selenium (Se) species in biological samples is a critical issue because Se commonly occurs at low levels and in diverse species. The method for the full quantification of Se species in serum samples was proposed through combined ion-pair reverse-phase (RP) chromatography and affinity chromatography (AF) hyphenated to inductively coupled plasma(quadrupole) mass spectrometry (ICP- $q \mathrm{MS}$ ) with post-column isotope dilution analysis (IDA) and a collision cell technique (CCT). Different Se species like inorganic $\mathrm{Se}\left(\mathrm{Se}^{4+}\right.$ and $\left.\mathrm{Se}^{6+}\right)$, selenocystine (SeCys), selenomethionine (SeMet), selenoprotein P (SelP), selenoalbumin (SeAlb) and glutathione peroxidase (GPx) can be separated and quantified. The proposed methodology was used to qualitatively and quantitatively study the dynamic distribution of Se species in human serum samples from the $\mathrm{Hg}$-contaminated area after supplementation with $100 \mu \mathrm{g}$ of Se daily as Se-enriched yeast for 180 days. SelP takes up almost half and even more of the total Se and increases with the Se administration. The repeatability in terms of relative standard deviation (R.S.D. $\%, n=10$ ) is $6 \%$ for

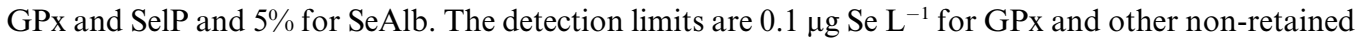

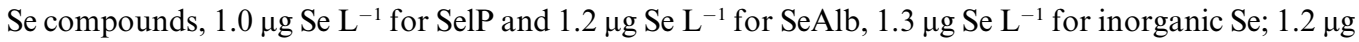

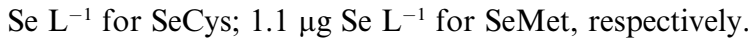

\section{Introduction}

Selenium (Se) is an essential micronutrient because of its unique antioxidant properties and its ability to regulate thyroid gland metabolism. ${ }^{1}$

As a well-known highly hazardous element, mercury $(\mathrm{Hg})$ can bring toxic effects to the immune system, kidneys, lungs, and nervous tissues, and is linked with a number of human health diseases. ${ }^{2}$ The town of Wanshan in Guizhou was once the major $\mathrm{Hg}$-mining area in China, where large-scale production of $\mathrm{Hg}$ lasted for more than 50 years before closure in 2002. Owing to the natural and anthropogenic factors, people living in this area suffered elevated $\mathrm{Hg}$ exposure and increased oxidative damage. ${ }^{3-5}$

${ }^{a}$ CAS Key Laboratory of Nuclear Analytical Techniques and CAS Key Laboratory for Biological Effects of Nanomaterials and Nanosafety, Institute of High Energy Physics, Chinese Academy of Sciences, Beijing, 100049, China. E-mail: chenchy@nanoctr.cn; Fax: +86-10-8823 3195; Tel: +86-10-8254 5560

${ }^{b}$ National Center for Nanoscience and Technology, Beijing, 100190, China ${ }^{c}$ National Food Institute, Technical University of Denmark, Copenhagen, DK-1790, Denmark

$\dagger$ This article is part of a themed issue highlighting outstanding and emerging work in the area of speciation.
A Se supplementation trial in persons exposed to $\mathrm{Hg}$ through fish consumption (in which most $\mathrm{Hg}$ is in an organic form as methylmercury) found reduced pubic hair $\mathrm{Hg}$ level, ${ }^{6}$ which suggested the reduced accumulation of $\mathrm{Hg}$ after Se supplementation. However, to the best of our knowledge, there is no investigation on the effects of Se supplementation in long-term $\mathrm{Hg}$-exposed populations living in $\mathrm{Hg}$-mining area, who are exposed mostly to inorganic and elemental $\mathrm{Hg}$. Therefore, a study was initiated to evaluate the effects of Se supplementation in $\mathrm{Hg}$-exposed volunteers from Wanshan $\mathrm{Hg}$-mining area. Hair, urine and blood samples were collected. Increased excretion of $\mathrm{Hg}$ was found after Se supplementation and the major $\mathrm{Hg}$ and Se species were characterized in the urine samples. ${ }^{7}$ However, no correlation between $\mathrm{Hg}$ and $\mathrm{Se}$ was found in these urine samples although the coaccumulation of $\mathrm{Se}$ and $\mathrm{Hg}$ in human and other mammalian organisms had been long found. ${ }^{8}$ As the extension of this work, the coaccumulation of $\mathrm{Se}$ and $\mathrm{Hg}$ in human serum samples will be further studied. In this study, however, only the Se species in serum samples before and after Se supplementation in these volunteers will be studied.

Se is mainly incorporated into three proteins in serum, i.e. glutathione peroxidase (GPx), selenoprotein $P$ (SelP) and albumin (SeAlb), which can be separated by anion exchange 
chromatography (AEC), ${ }^{\mathbf{9}, 10}$ size exclusion chromatography $(\mathrm{SEC})^{\mathbf{1 1}}$ or affinity chromatography (AC)..$^{9,12,13}$ However, quantitative study could only find about $90.7 \%{ }^{10}$ and $85.9-92.5 \%{ }^{9}$ of total $\mathrm{Se}$ in serum. About $10 \%$ of total $\mathrm{Se}$ in serum is still unidentified.

Information on the presence of selenoamionacids and inorganic Se in serum is scarce. Previous work has established and optimized analytical methods to identify and quantify selenoaminoacids and inorganic Se in biological samples by reversephase chromatography (RP). ${ }^{7,14-16}$ To our knowledge, there were few articles to qualitatively and quantitatively determine both small molecular selenocompounds and Se-containing proteins in human serum samples. Therefore, in this study we proposed a method by the combination of RP and AF chromatography coupled to ICP-MS. Through the proposed method, Se-containing proteins (SelP, SeAlb, GPx), and small selenocompounds like SeCys, SeMet, inorganic Se in serum in $\mathrm{Hg}$-exposed people after Se supplementation can be separated and quantified by RP and AF-ICP- $q \mathrm{MS}$ with post-column isotope dilution analysis (IDA) and a collision cell technique (CCT). The dynamic distribution of Se species in human serum samples will also be studied.

\section{Experimental}

\section{Instrument}

A Symmertryshield RP18 column $(150 \times 3.9 \mathrm{~mm}$, Waters, Milford, USA) and affinity "HiTrap-heparin" sepharose (1 mL) and "HiTrap-blue" sepharose (1 mL) columns (Pharmacia, Uppsala, Sweden) were employed for the separation of the small molecular Se compounds and selenocontaining proteins. The columns were connected to a HPLC system consisting of a liquid chromatography pump (WAT055028 metal-free 626 pump, Waters, Milford, USA). A six-way Rheodyne valve (Model 5012) was also used for affinity chromatography. The continuous addition of the spike was performed by a peristaltic pump (Model HP4, Scharlau Science, Barcelona, Spain). Samples were loaded with a syringe into a $100 \mu \mathrm{L}$ sample loop. All separations were performed at room temperature. UV measurements were performed with a Waters 484 UV/VIS absorption detector (Waters Corporation, MA, USA). All solutions were prepared with Milli$\mathrm{Q}$ water $(18.2 \mathrm{M} \Omega \mathrm{cm})$, and filtrated with a $0.22 \mu \mathrm{m}$ microporous membrane. The column was connected directly to the nebulizer of the ICP-MS system with polyether ether ketone (PEEK) tubing $(0.13 \mathrm{~mm}$ i.d.). The signal of ICP-MS was triggered by the manual injector of the HPLC. A Thermo Elemental X7 ICP-MS (Thermo Electron Co., USA) was used as the element detector. Optimization was carried out daily with a normal tuning solution (1 ng mL ${ }^{-1}, \mathrm{Be}, \mathrm{Co}$, In, U). Raw data were collected by the PlasmaLab software through a personal computer. The peak areas of elemental signals of ICP-MS were used for quantitative analysis online. A continuous flow of $7.5 \mathrm{~mL} \mathrm{~min}^{-1}$ of hydrogen and helium was introduced into the collision cell as reaction gas. The sample introduction system consisted of a classical Meinhard nebuliser with a Scott double-pass quartz spray chamber cooled down to $2{ }^{\circ} \mathrm{C}$. The collision cell technique (CCT) was employed for the elimination of the polyatomic interferences of ${ }^{40} \mathrm{Ar}^{40} \mathrm{Ar}$ and others in the detection of ${ }^{80} \mathrm{Se}$. The ICP-MS and the

Table 1 The instrumental Parameters of ICP-MS and HPLC

Plasma parameters

Power

Plasma Ar flow rate

Carrier Ar flow rate

Nebulization Ar rate

Isotopes monitored

Acquisition mode

Reverse-

Column

Mobile phase A

Mobile phase B

Gradient program

Flow rate

Pressure

Affinity column HPLC Conditions

Columns

Injection volume

Flow rate

Pressure

Mobile phase A

Mobile phase B

Gradient program
CCT gas and the flow rate

Dwell time for each isotope

Injection volume

$1350 \mathrm{~W}$

$13 \mathrm{~L} \mathrm{~min}^{-1}$

$0.75 \mathrm{~L} \mathrm{~min}^{-1}$

$0.84 \mathrm{~L} \mathrm{~min}^{-1}$

$92.72 \%(\mathrm{He})+7.29 \%\left(\mathrm{H}_{2}\right), 7.5 \mathrm{~mL}$ $\min ^{-1}$

Se: $76,77,78,80,82$

$10 \mathrm{~ms}$

Time resolved analysis

tions

Symmertryshield RP18, $150 \times 3.9$ $\mathrm{mm}$

$0.3 \% \mathrm{CH}_{3} \mathrm{OH}+0.1 \% \mathrm{HFBA}$

$5 \% \mathrm{CH}_{3} \mathrm{OH}+0.1 \%$ HFBA

0-4 min, mobile phase A, 4-12 min, mobile phase $\mathrm{B}$

$1.0 \mathrm{~mL} \mathrm{\operatorname {min } ^ { - 1 }}$

$0.1 \mathrm{~mL}$

1700 Psi

Hitrap heparin-sepharose (1 mL), Hitrap blue-sepharose $(1 \mathrm{~mL})$

$0.1 \mathrm{~mL}$

$0.8 \mathrm{~L} \mathrm{~min}^{-1}$

250 Psi

Binding buffer, ammonium acetate, $0.05 \mathrm{~mol} \mathrm{~mL}^{-1}, \mathrm{pH} 7$

Elution buffer, ammonium acetate, $1.5 \mathrm{~mol} \mathrm{~mL}^{-1}, \mathrm{pH} 7$

0-5 min, position 1 (P1), mobile phase A; 5-10 min, position 2 (P2), mobile phase B; 10-15 min, position $1(\mathrm{P} 1)$, mobile phase $\mathrm{B}$; 15-20 min, position 1(P1), mobile phase A

HPLC operating conditions used in this work are summarized in Table 1.

\section{Reagents and standards}

All reagents were of analytical reagent grade. Heptafluorobutanoic acid (HFBA) was purchased from Fluka (Switzerland), while Triton X-100 from Amersco (USA). Ammonium acetate and nitric acid were obtained from Beihua (China), while methanol from Guangfu (China). Enriched ${ }^{78} \mathrm{Se}$ was obtained from Cambridge Isotope Laboratories (USA).

Stock standard solutions of $100 \mathrm{mg} \mathrm{Se} \mathrm{L}^{-1}$ were prepared in deionized water from selenocysteine (Sigma, St. Louis, USA), selenomethionine (Sigma, St. Louis, USA), sodium selenate $\left(\mathrm{Na}_{2} \mathrm{SeO}_{4}\right.$, Alfa Aesar), sodium selenite $\left(\mathrm{Na}_{2} \mathrm{SeO}_{3}\right.$, Zhonglian, China). The working standard solutions were prepared in Milli$\mathrm{Q}$ water by dilution of stock solutions as required daily and stored in the dark.

\section{Collection and preparation of serum samples}

Whole blood samples were collected from 53 volunteers from Wanshan Hg-mining area who had been supplemented with 100 $\mu \mathrm{g}$ of Se per day from day 0 to 180 in the form of Se-enriched yeast (SelenoPrecise, Pharma Nord, Denmark). The blood samples were collected on day 0 to day $30,60,90,120,150,180$ and 360 , where day 0 was the day before the supplementation 
and day 30 to $60,90,120,150,180$, and 360 were the corresponding days after supplementation. The blood samples of at least $5 \mathrm{~mL}$ were collected in the morning after overnight fasting. The serum samples were obtained by centrifugation $(10 \mathrm{~min}$ at $1500 \mathrm{~g}) 2-4 \mathrm{~h}$ after blood collection and stored at $-20^{\circ} \mathrm{C}$ until analysis. Serum samples were analyzed within a week after the collection.

Serum samples were simply $1: 4$ diluted with $0.05 \mathrm{~mol} \mathrm{~L}^{-1}$ ammonium acetate $(\mathrm{pH}=7)$ and centrifuged at $10000 \mathrm{~g}$ for 30 min by centrifugal filtration tube (molecular weight cut off at $3000 \mathrm{Da}$ ). Supernatant (molecular weight $>3000 \mathrm{Da}$ ) is prepared for quantitative analysis of GPx, SelP and SeAlb, while lowerlayer liquid (molecular weight $<3000 \mathrm{Da}$ ) is used for quantitative analysis of $\mathrm{Se}^{4+}$ and $\mathrm{Se}^{6+}$ (inorganic $\mathrm{Se}$ ), SeCys, and SeMet. Prior to injection, all samples were filtrated with $0.45 \mu \mathrm{m}$ microporous membrane.

\section{Analytical procedures}

Total Se concentration analysis. To measure the total amount of Se, serum samples diluted by $1: 4$ with solution $\left(0.1 \% \mathrm{HNO}_{3}\right.$ $+0.1 \%$ HFBA $+0.1 \%$ Triton X-100) were directly introduced into ICP- $q \mathrm{MS}$ by $2 \%(\mathrm{v} / \mathrm{v}) \mathrm{HNO}_{3}$. The recovery was $97 \%$ by using human serum reference materials BCR-637 from our experiments. The ICP-MS condition, which was the same as Se speciation, shown in Table 1.

Ion-pair reverse-phase chromatography. Using reverse-phase ion-pair chromatography for separation of Se compounds can be found in a large number of papers. ${ }^{15-19}$ We also adopted this method to study the Se species in urine and other biological samples. ${ }^{7,14}$ Here, the ICP-MS and chromatographic conditions were optimized for the separation of Se species in human serum (inorganic Se, SeCys, and SeMet). Calibration curves were used for quantification of these Se species and mixed standards of $\mathrm{Se}^{4+}$

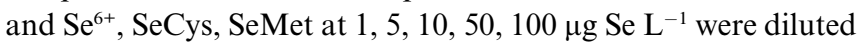
as required daily.

Affinity chromatography. The fractionation of Se-containing proteins in human serum was achieved by affinity chromatography. ${ }^{9,12}$ The operating and chromatographic conditions are shown in Table 1 and the whole experimental arrangement is shown in Fig. 1.

In Fig. 1, the heparin-sepharose column 1 can selectively retain SelP, while the blue sepharose 2 can retain both SelP and albumin. The serum samples first passed through both column 1 and 2 using mobile phase A, where SelP was retained in column 1 and SeAlb in column 2 at position 1 (P1). GPx and other nonretained Se compounds were first eluted since they lack affinity for heparin or blue-sepharose. Then mobile phase B was used to elute SelP at position 2 (P2). The SeAlb was eluted using mobile phase $\mathrm{B}$ at $\mathrm{P} 1$, then mobile phase $\mathrm{A}$ was used at $\mathrm{P} 1$ for the preparation of the next injection. The outlet of the chromatographic column was connected through a T-piece where an enriched ${ }^{78} \mathrm{Se}$ spike was continuously added with a flow rate of $0.8 \mathrm{~mL} \mathrm{~min}^{-1}$ and the mixture was nebulized into the plasma for the measurement of the Se in binding proteins in human serum.

Species-unspecific isotope dilution analysis. As is known, one of the most important advantages of the use of the species-unspecific spiking is the possibility to determine the level of certain element in a compound without knowing the structure and composition. ${ }^{9,20}$ After correcting for dead time, spectral interference and mass bias, the isotope ratio chromatogram was converted into the mass flow chart by the isotope ratio equation calculation. The absolute elemental amount in the different protein fractions could be calculated by the integration of the corresponding peaks in the mass flow chart. ${ }^{9}$

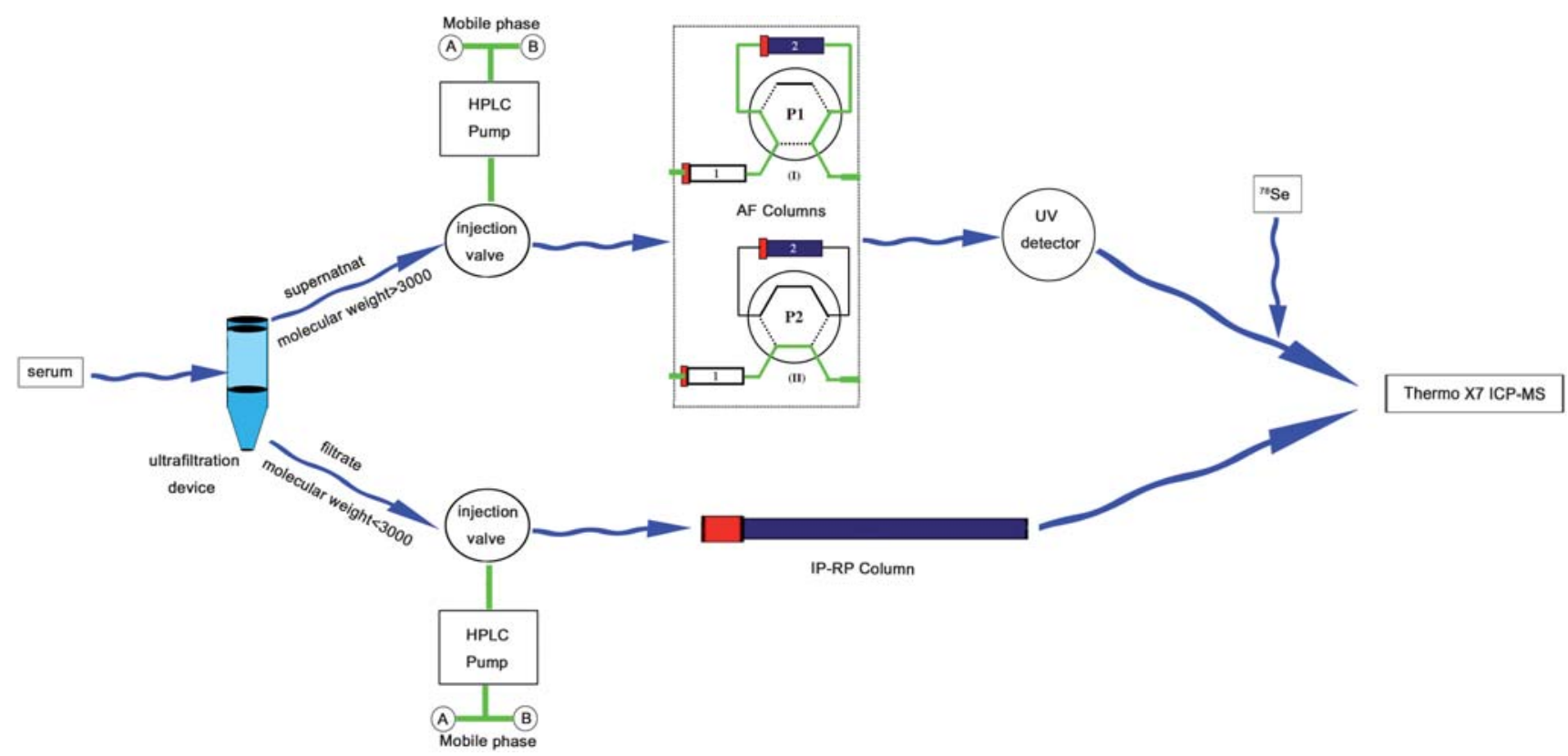

Fig. 1 Scheme of Se species analysis in human serum including small Se compounds and Se-containing proteins by ion-pair reverse-phase chromatography and affinity chromatography coupled to post-column isotope dilution analysis ICP-MS, where in the AF columns, column 1 is heparin sepharose, column 2 is blue-sepharose. 


\section{Results and discussion}

\section{Separation and quantification of small molecular} selenocompounds

As is known to all, the $\mathrm{pH}$ value and methanol concentration in the mobile phase and the concentrations of ion-pair reagents can affect the separation efficiency of small molecular selenocompounds. Here, chromatographic parameters, such as the concentrations of HFBA and methanol was further changed and optimized. When mobile phase contained $2 \% \mathrm{CH}_{3} \mathrm{OH}$ and $0.1 \%$ HFBA, peaks obtained from aqueous SeMet standard was broader and the elution time was longer than that using the mobile phase containing 5\% $\mathrm{CH}_{3} \mathrm{OH}$ and $0.3 \%$ HFBA. Consequently, the later was also used to reduce the elution time of SeMet.

The chromatogram of the small molecular Se compounds is shown in Fig. 2. It is hard to separate $\mathrm{Se}^{4+}$ and $\mathrm{Se}^{6+}$. However, the separation of $\mathrm{Se}^{4+}$ and $\mathrm{Se}^{6+}$ in serum samples can be achieved by using anion exchange column that was reported in our other paper. ${ }^{21}$ We found that $\mathrm{Se}^{4+}$ is the major inorganic $\mathrm{Se}$ forms but only accounts for $1.8 \%$ to $2.6 \%$ of total Se.

Calibration curves based on peak area were linear with correlation coefficients $\left(r^{2}\right)$, which is better than 0.9992 for each species in the range studied $\left(1-100 \mathrm{ng} \mathrm{mL}^{-1}\right)$. The detection limits were estimated based on the concentration (as element) necessary to yield a net signal equal to three times the standard deviation of the background. The IP-RP-HPLC method detection limits (as element) were $1.3,1.2$, and $1.1 \mathrm{ng} \mathrm{mL}{ }^{-1}$ for $\mathrm{Se}^{4+}$ and $\mathrm{Se}^{6+}$, SeCys, SeMet, respectively.

\section{Quantification of SelP, SeAlb, GPx and other non-retained Se compounds by AF-IDA-ICP-qMS}

Fig. 3 shows the separation and isotope dilution analysis of Secontaining proteins in serum. It is well known for isotope ratio accurate measurements, every intensity value in the chromatogram had to be corrected for the dead time, which was $35 \mathrm{~ns}$ using the usual correction equation.,22,23 After dead time and mass bias correction, the corrected final mass flow chromatograms in Fig. 3(b) were evaluated from the ratios of ${ }^{80} \mathrm{Se} /{ }^{78} \mathrm{Se}$ in Fig. 3(a) using the online isotope equation. ${ }^{20}$ The intensity of a protein was monitored by UV at $254 \mathrm{~nm}$ online as shown in Fig. 3(c). The application of ion-guiding multipole collision cells

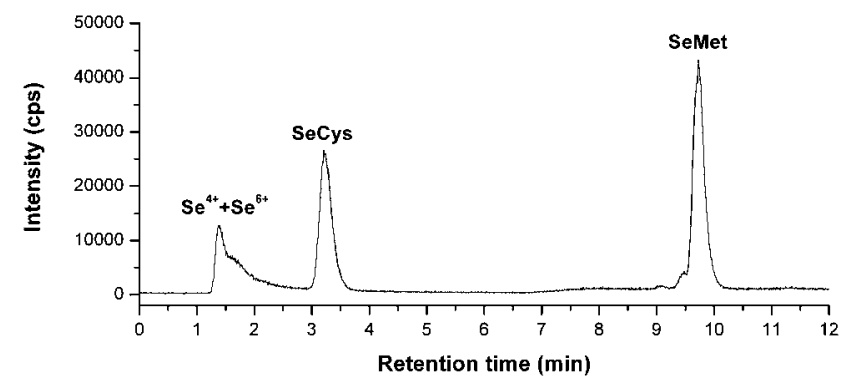

Fig. 2 Chromatogram of the small molecular Se compounds in a serum sample. Column: Symmertryshield RP18, $150 \times 3.9 \mathrm{~mm}$, mobile phase: A, $0.3 \% \mathrm{CH}_{3} \mathrm{OH}+0.1 \% \mathrm{HFBA}, \mathrm{B}, 5 \% \mathrm{CH}_{3} \mathrm{OH}+0.3 \% \mathrm{HFBA}, 0-4 \mathrm{~min}$,

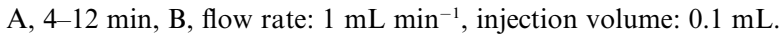
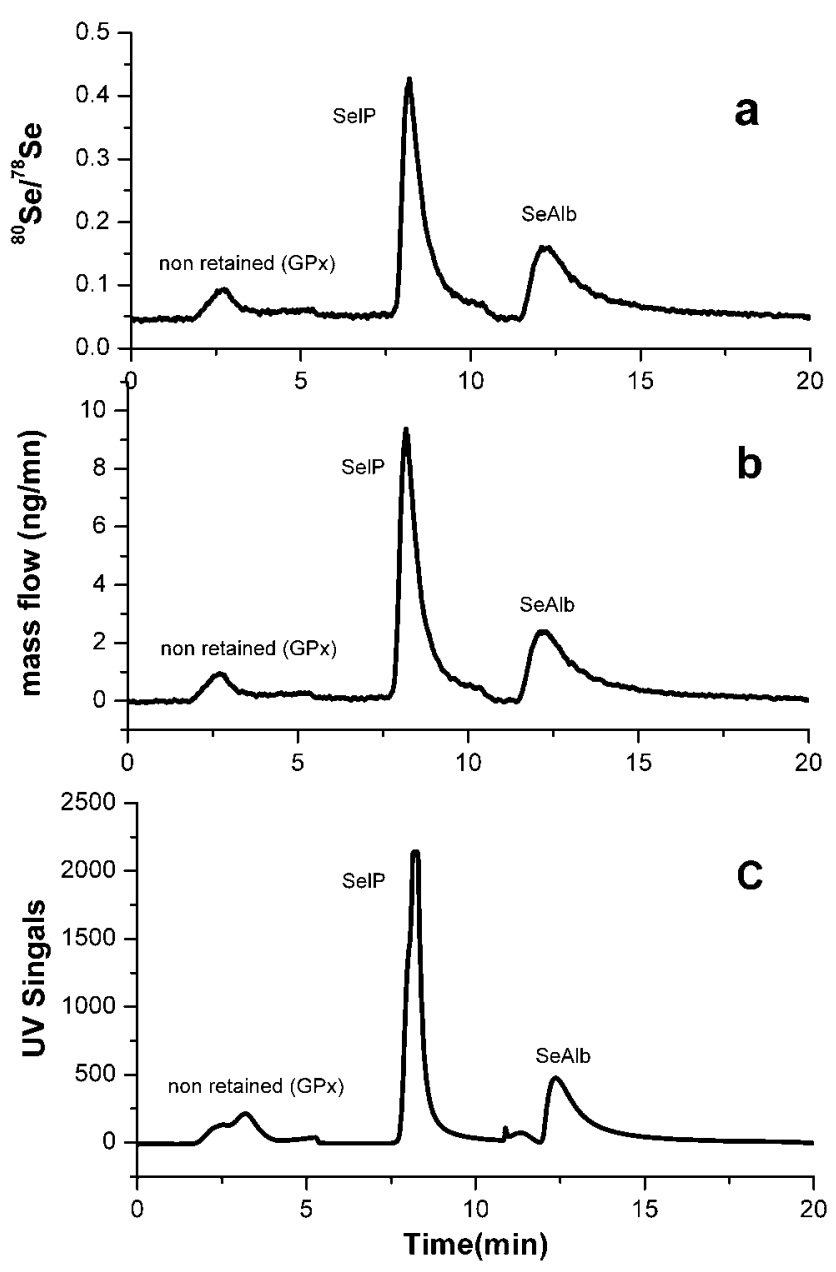

Fig. 3 (a), Corresponding Se isotope ratio chromatograms for ${ }^{80} \mathrm{Se} /{ }^{78} \mathrm{Se}$ after mathematical corrections. (b), Mass flow chromatogram obtained for ${ }^{80} \mathrm{Se} /{ }^{78} \mathrm{Se}$ isotope ratios in a serum sample by AF-HPLC. (c), Corresponding UV signal $(\lambda=254)$ of GPx and non-retained Se compounds, SelP, SeAlb in a serum sample.

in ICP-MS using helium as a buffer and hydrogen as a reaction gas is an effective means of reducing or even suppressing argon induced polyatomic ion interferences, ${ }^{40} \mathrm{Ar}{ }^{40} \mathrm{Ar}$ and ${ }^{38} \mathrm{Ar}{ }^{40} \mathrm{Ar}$, on the main Se isotopes ${ }^{80} \mathrm{Se}$ and ${ }^{78} \mathrm{Se}$, respectively.

The use of affinity chromatography by a heparin-sepharose column coupled to a reactive blue-sepharose column allows for a rapid, precise and convenient fractionation of the three main Se-containing proteins in human serum (GPx, SelP and SeAlb). The repeatability in terms of relative standard deviation (R.S.D. $\%, \mathrm{n}=10$ ) is $6 \%$ for GPx and SelP and 5\% for SeAlb. The detection limits are also calculated according to the $3 \mathrm{~s}$ criterion. LODs are $0.1 \mu \mathrm{g} \mathrm{Se} \mathrm{L}^{-1}$ for GPx and other non-retained Se

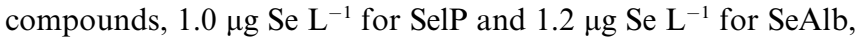
respectively.

\section{Full quantification of both small molecular selenocompounds and selenoproteins in serum samples from one subject}

The quantitative results of inorganic Se, SeCys, SeMet, GPx, SelP and SeAlb in serum samples from one subject before and after Se supplementation through the combined application of 


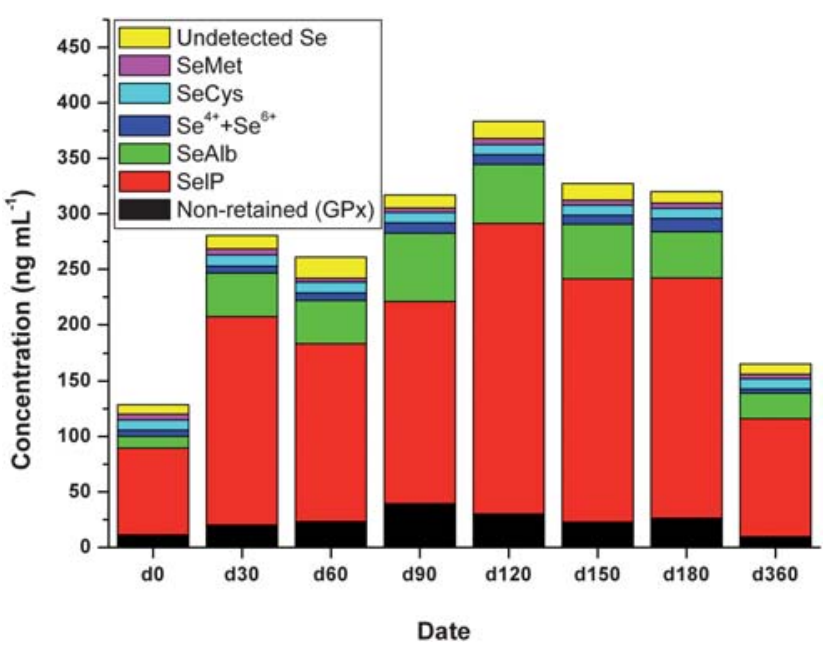

Fig. 4 Time-dependent concentrations of Se species in serum samples of one of the Hg-exposed subjects supplemented with Se enriched yeast. Data represent the average values of three independent determinations.

RP and AF columns hyphenated to ICP-MS are shown in Fig. 4. The undetected Se species was calculated as the total Se contents minus all the detected Se species.

It was found that the total Se significantly increased after $\mathrm{Se}$ supplementation by day 0 to day 180 , whereas it dropped after the cease of Se supplementation on day 360. It should be noted that the Se level in serum after Se supplementation (d360) are still higher than that before Se supplementation (d0) even after 6 months, which suggest organic Se (Se-enriched yeast in our case) supplementation is efficient to increase serum Se concentrations and this is in agreement with other studies. ${ }^{24}$

The distribution of Se in different Se species in serum samples from one subject on different days is shown in Table 2. On day 0 , Se in SelP, SeAlb and GPx accounts for $61 \%, 8.1 \%, 8.7 \%$ of total $\mathrm{Se}$, where the distribution of SelP and SeAlb are almost the same as other study but the GPx is less than other study. ${ }^{9}$ In the study by Reyes et al., the GPx peak stands also for the non-retained Se compounds, which may be the small molecular Se compounds in our study. Therefore, if the small molecular Se compounds are considered, which accounts for $15.7 \%$ of total Se, our results also agree well with their finding. ${ }^{9}$

On day 0 , trace amount of Se in inorganic Se, SeCys and SeMet in serum sample were found, which accounts for $4.4 \%$, $7.1 \%$ and $4.2 \%$ of total Se, respectively. Using SEC, Palacios

Table 2 Se distribution (\%) in fractions of human serum samples of one of the Hg-exposed subjects supplemented with Se-enriched yeast

\begin{tabular}{lllllll}
\hline & \multicolumn{2}{l}{$\begin{array}{l}\text { Non-retained } \\
\text { Date }\end{array}$} & \multicolumn{3}{c}{ GPx $)$} & \multicolumn{3}{c}{ SelPSeAlbSe ${ }^{4+}+\mathrm{Se}^{6+}$ SeCys SeMetSe } \\
\hline Day 0 & 8.7 & 61.08 .1 & 4.4 & 7.1 & 4.2 & 6.5 \\
Day 30 & 7.2 & 66.714 .0 & 2.2 & 3.6 & 1.9 & 4.3 \\
Day 60 & 8.9 & 61.514 .6 & 2.7 & 3.7 & 1.4 & 7.3 \\
Day 90 12.4 & 57.319 .4 & 3.0 & 2.9 & 1.3 & 3.7 \\
Day 1207.9 & 68.113 .9 & 2.3 & 2.4 & 1.4 & 4.0 \\
Day 1507.0 & 66.815 .0 & 2.5 & 2.8 & 1.4 & 4.6 \\
Day 1808.2 & 67.413 .0 & 3.7 & 2.9 & 1.5 & 3.2 \\
Day 3605.8 & 64.413 .8 & 2.3 & 5.5 & 2.5 & 5.6 \\
\hline
\end{tabular}

et al. ${ }^{11}$ did not find such Se molecules, however, this may be attributed to the poor resolving power of SEC. In our study, the undetected Se on d0 through our method accounts for $6.5 \%$ of total Se, which suggests other Se species exist.

After Se supplementation, the distribution of Se in SelP and SeAlb increased from $61.0 \%$ to $64.6 \%$ and $8.1 \%$ to $14.9 \%$, respectively, while for the inorganic Se, SeCys and SeMet, it decreased from $4.4 \%$ to $2.7 \%, 7.1 \%$ to $3.1 \%$ and $4.2 \%$ to $1.5 \%$, respectively. The distribution of Se in GPx did not change too much, which is $8.7 \%$ and $8.6 \%$ before and after Se supplementation. Our results find that most of the supplemented Se went to SeAlb, which is in agreement with the findings by Palacios et al. ${ }^{11}$

On day 360 , when the Se supplementation ceased for 6 months, the Se distribution in SelP and SeAlb is still higher than that on day 0, while for GPx and other non-retained Se compounds, inorganic Se, SeCys and SeMet, it is lower than that on day 0. This may suggest that SelP and SeAlb may serve as the Se pool in the body while GPx etc. can serve as the indicator of Se intake in the body.

Organic Se is more efficient at increasing serum Se concentrations but not necessarily increasing Se status such as GPx. The findings of this study show that the concentration of Se species will reach the top after Se supplementation, i.e., Se in GPx, SelP and $\mathrm{SeAlb}$ reach the maximum distribution on day 90, day 120 and day 90 , respectively, but the distribution did not change too much in the supplementation phase. It can therefore be concluded that long-term Se supplementation is suitable to increase and thus improve the body Se pools.

Generally, Se can antagonize the toxicity of $\mathrm{Hg}$ in mammals, which is presumably attributed to the formation of biologically inert $\mathrm{Se}-\mathrm{Hg}$ compounds. ${ }^{25} \mathrm{An}$ attempt to search for the possible inert $\mathrm{Se}-\mathrm{Hg}$ compounds in the serum samples is still under way in our lab.

\section{Conclusions}

Analysis of Se species (including $\mathrm{Se}^{4+}+\mathrm{Se}^{6+}$, SeCys, SeMet, GPx, $\mathrm{SelP}$, and SeAlb) in human serum samples is proposed by HPLCICP- $q$ MS through ion-pair reversed phase chromatography and affinity chromatography with on-line isotope dilution.

The present methodology was applied to study the dynamic distribution of $\mathrm{Se}$ in serum samples in long-term $\mathrm{Hg}$ exposed people before and after Se supplementation. Se in SelP, SeAlb and GPx accounts for over $77 \%$ of total Se while Se in inorganic Se, SeCys and SeMet accounts for about $15 \%$ of total Se before Se supplementation. After Se supplementation, the distribution of Se in SelP and SeAlb increased, while decreasing for the inorganic Se, SeCys and SeMet. The distribution of Se in GPx did not change too much before and after Se supplementation. Our results indicate that most of the supplemented Se are bound to SeAlb. Long-term Se supplementation is suitable to increase and thus improve the body Se pools even in Hg-exposed people.

\section{Acknowledgements}

This work is supported by NSFC/RGC Joint Research Scheme (20931160430), the Knowledge Innovation Programme of the Chinese Academy of Sciences (KJCX3.SYW.N3), International 
Atomic Energy Agency (CPR-15818), and the EU sixth Framework Programme (FOOD-CT-2006-016253).

\section{References}

1 P. O. Amoako, P. C. Uden and J. F. Tyson, Anal. Chim. Acta, 2009, 652, 315-323.

2 K. Yoshizawa, E. B. Rimm, J. S. Morris, V. L. Spate, C. Hsieh, D. Spiegelman, M. J. Stampfer and W. C. Willett, N. Engl. J. Med., 2002, 347, 1755-1760.

3 C. Chen, L. Qu, B. Li, L. Xing, G. Jia, T. Wang, Y. Gao, P. Zhang, M. Li, W. Chen and Z. Chai, Clin. Chem., 2005, 51, 759-767.

4 C. Chen, H. Yu, J. Zhao, B. Li, L. Qu, S. Liu, P. Zhang and Z. Chai, Environ. Health Perspect., 2006, 114, 297-301.

5 Y.-F. Li, C. Chen, L. Xing, T. Liu, Y. Xie, Y. Gao, B. Li, L. Qu and Z. Chai, Nucl. Technol., 2004, 27, 899-903.

6 K. Seppanen, M. Kantola, R. Laatikainen, K. Nyyssonen, V. P. Valkonen, V. Kaarlopp and J. T. Salonen, J. Trace Elem. Med. Biol., 2000, 14, 84-87.

7 Y.-F. Li, C. Chen, B. Li, Q. Wang, J. Wang, Y. Gao, Y. Zhao and Z. Chai, J. Anal. At. Spectrom., 2007, 22, 925-930.

8 L. Kosta, A. R. Byrne and V. Zelenko, Nature, 1975, 254, 238-239.

9 L. H. Reyes, J. M. Marchante-Gayon, J. I. G. Alonso and A. SanzMedel, J. Anal. At. Spectrom., 2003, 18, 1210-1216.

10 M. Xu, L. Yang and Q. Wang, J. Anal. At. Spectrom., 2008, 23, 1545-1549.

11 O. Palacios, J. R. Encinar, D. Schaumloffel and R. Lobinski, Anal. Bioanal. Chem., 2006, 384, 1276-1283.
12 P. Jitaru, M. Prete, G. Cozzi, C. Turetta, W. Cairns, R. Seraglia, P. Traldi, P. Cescon and C. Barbante, J. Anal. At. Spectrom., 2008, 23, 402-406.

13 P. Jitaru, M. Roman, G. Cozzi, P. Fisicaro, P. Cescon and C. Barbante, Microchim. Acta, 2009, 166, 319-327.

14 H. Yu, C. Chen, Y. Gao, B. Li and Z. Chai, Chin. J. Anal. Chem., 2006, 34, 749-753.

15 M. Kotrebai, J. F. Tyson, E. Block and P. C. Uden, J. Chromatogr., A, 2000, 866, 51-63.

16 M. Montes-Bayón, T. D. Grant, J. Meija and J. A. Caruso, J. Anal. At. Spectrom., 2002, 17, 1015-1023.

17 S. Afton, K. Kubachka, B. Catron and J. A. Caruso, J. Chromatogr., $A, 2008,1208,156-163$.

18 P. Cuderman, I. Kreft, M. Germ, M. Kovacevic and V. Stibilj, J. Agric. Food Chem., 2008, 56, 9114-9120.

19 W. Wang, Z. Chen, D. E. Davey and R. Naidu, Microchim. Acta, $2009,165,167-172$.

20 P. Rodriguez-Gonzalez, J. M. Marchante-Gayon, J. I. G. Alonso and A. Sanz-Medel, Spectrochim. Acta, Part B, 2005, 60, 151207.

21 L. Hu, Z. Dong, X. Huang, Y.-F. Li, B. Li, L. Qu, G. Wang, Y. Gao and C. Chen, Chin. J. Anal. Chem, 2010, in press.

22 J. G. Alonso, Anal. Chim. Acta, 1995, 312, 57-78.

23 C. S. Muniz, J. M. M. Gayon, J. I. G. Alonso and A. Sanz-Medel, J. Anal. At. Spectrom., 1999, 14, 1505-1510.

24 G. Alfthan, A. Aro, H. Arvilommi and J. K. Huttunen, Am. J. Clin. Nutr., 1991, 53, 120-125.

25 K. T. Suzuki, C. Sasakura and S. Yoneda, Biochim. Biophys. Acta, Protein Struct. Mol. Enzymol., 1998, 1429, 102-112. 